\title{
AS FORMAS DE PROVIMENTO NA GESTÃO DEMOCRÁTICA DA EDUCAÇÃO PÚBLICA E SEUS IMPACTOS NA VALORIZAÇÃO DOCENTE
}

\author{
Provision ways in democratic management of public \\ education and their impacts on teacher appreciation
}

\section{Las formas de provisión en la gestión democrática de la educación pública y sus impactos en la valorización docente}

\begin{abstract}
RESUMO O artigo apresenta estudo acerca da configuração da gestão democrática da escola pública de um município localizado na Mesorregião Sudeste do Estado do Paraná. Analisamos as influências das atuais formas de provimento ao cargo de diretor escolar, ponderando se elas proporcionam a valorização da carreira docente. Conforme as considerações dos expoentes da área da gestão democrática da escola e da valorização docente, bem como, mediante fontes empíricas e dados públicos sobre o processo de eleição para gestores do município, identificamos algumas disparidades no que tange às formas de provimento, principalmente para os cargos de direção e/ou coordenação nos espaços da Educação Infantil, desencadeando assim formas mistas de escolhas. As formas de provimento representam o viés democrático da escola pública, mas a possível adesão a princípios tecnocráticos na gestão acaba influenciando na valorização da carreira docente.
\end{abstract}

PALAVRAS-CHAVE: GESTÃo ESCOLAR. FoRMAS DE PROVIMENTO. VALORIZAÇÃO DOCENTE. DEMOCRACIA.

ABSTRACT The article presents a study on the configuration of democratic management in public school in a town localized in the mesoregion of Southwest of the State of Paraná, Brazil. We analyzed influences from current ways to the appointment of school principal, considering whether they provide the appreciation of the teaching carrier. According to the considerations of exponents of the democratic management area of school and of the teaching appreciation, as well as before empirical sources and public data on the process of election of managers of the town, we identified some disparities on the appointment ways, mainly for principal and/or coordination positions in the spaces of Child Education, then triggering mixed ways of choice. Some ways of appointment represent the public school democratic bias, but the possible adhesion to technocratic principles in management influences on the appreciation of the teaching carrier.

KEY-WORDS: SCHOOL MANAGEMENT. WAYS OF APPOINTMENT. TEACHING APPRECIATION. DEMOCRACY.

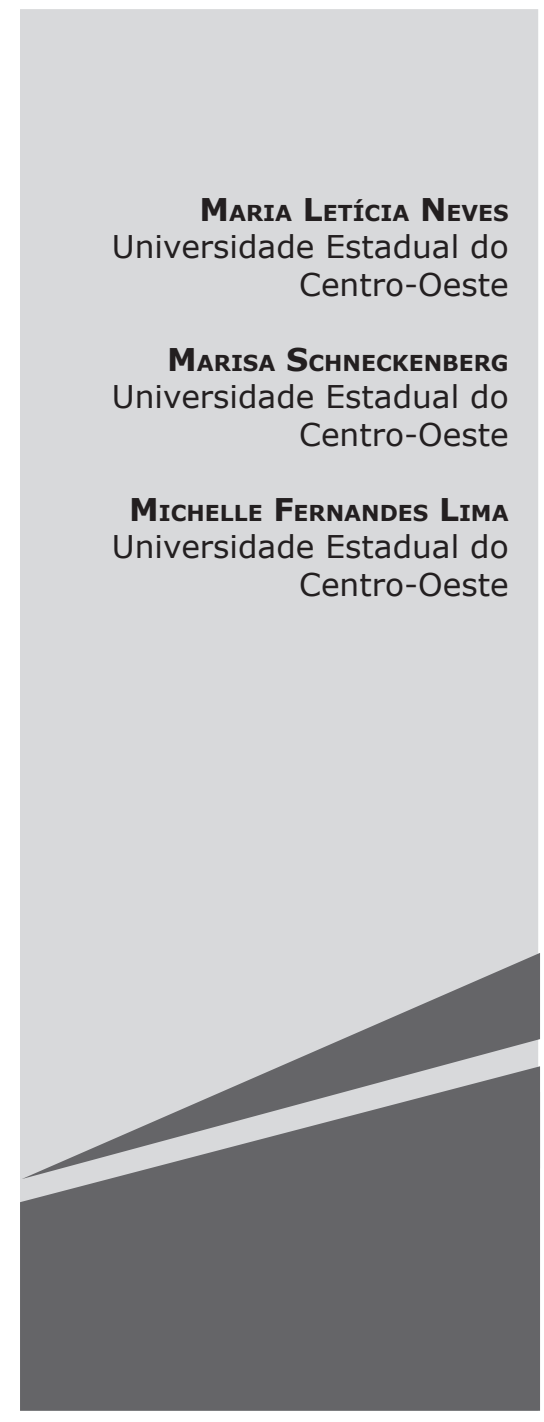


RESUMEN El artículo presenta un estudio sobre la configuración de la gestión democrática en un municipio ubicado en la mesorregión del Estado de Paraná, Brasil. Analizamos las influencias de las actuales formas de designación para la posición de director de escuela, ponderando si ellas proporcionan la valorización de la carrera docente, también con fuentes empíricas y datos públicos sobre el proceso de elección para gestores en el municipio, identificamos algunas disparidades cuanto a las formas de designación, principalmente para las posiciones de director y/o coordinación de espacios de Educación Infantil, lo que desencadena formas mistas de selección. Las formas de designación representan un enfoque democrático de la escuela pública, pero la posible adhesión a principios tecnocráticos en la gestión hay influenciado en la valorización de la carrera docente.

PALABRAs CLAVE: GESTIÓN ESCOLAR. Formas dE DESIGNACIÓN. VALORIZACIÓN DOCENTE. DEMOCRACIA.

\section{INTRODUÇÃo}

A escola, nas últimas décadas, vem sendo cada vez mais problematizada sob diferentes aportes teóricos nos estudos acadêmicos. Pesquisas que versam sobre a qualidade e, ao mesmo tempo, a democratização do ensino público, permeiam o campo científico em Educação. Ainda é pertinente mencionar o papel do pesquisador em políticas educacionais: ao exercer a tarefa de análise, necessita expor seu posicionamento para que seu estudo possua reflexividade epistemológica. Em outras palavras, uma pesquisa sólida e coerente, em que o investigador assume uma postura ética e, também, um compromisso social para com a realidade que se insere.

As pesquisas delimitam-se conforme certo tempo histórico. Partindo dessa constatação compreendemos que, mediante o decorrer da história, precisamente no período de reabertura política do país para o sistema democrático, as pesquisas em políticas educacionais começaram a apresentar, como problemática, a interferência do Estado na Educação. Além dela, também a função social da escola na formação dos cidadãos, e tudo isso repercutiu diretamente nas formas de organização e administração dos espaços públicos escolares.
Necessitamos salientar que o nosso país possui uma longa história referente a sistemas políticos de governo e possibilidades democráticas, tanto na gestão pública como escolar. Segundo Hypólito et al. (2008, p. 69), assim se configura a realidade brasileira:

Em nosso país predomina uma democracia de baixíssima intensidade, com longos períodos de ditadura militar e regimes de exceção, sobre uma base colonial de quase quatro séculos de escravidão, na qual está enraizada uma cultura racista, excludente a autoritária que permeia toda a sociedade. Neste sentido, a empreitada utópica se faz mais difícil, contudo, não menos importante e fundamental.

As lutas desencadeadas por inúmeros movimentos sociais fizeram os governos observarem o sistema educativo sob um novo ponto de vista, em que todos, inclusive aqueles oriundos das camadas populares, tivessem seus direitos assegurados sob termos de leis. Como exemplo, podemos citar o acesso à escola, partindo do princípio que a educação pública e de qualidade é um direito de todos. 
Assim, Esquinsani (2013, p. 102, grifo do autor) expõe que há uma forte relação quanto ao estímulo ao acesso como eixo basilar do sucesso escolar.

O descompasso entre o acesso e o sucesso escolar tem se materializado em um cenário sobre o qual ocorrem reações que se processam em duas perspectivas: por um lado, são inegáveis e elogiosos os esforços públicos e privados comprometidos com a concretização de políticas públicas que garantam a qualidade na educação, e por outro lado, há um intenso movimento acadêmico, reforçando discussões sobre a tão aludida qualidade.

A qualidade da educação remete à ideia de gestão. A gestão escolar pode ser considerada um indicador de qualidade educacional, onde os recursos advindos para a escola sejam bem administrados, para que os benefícios sejam realidades concretas. Diante disso, Carvalho (2008, p. 5) salienta:

A gestão democrática da escola pública, entendida como sinônimo de participação da comunidade, autonomia e descentralização administrativa, vem ganhando ênfase nas políticas educacionais encaminhadas no Brasil, a partir da década de 9o, especialmente a Lei de Diretrizes e Bases da Educação Nacional (Lei 9394/96). Propõe-se como principais instrumentos de gestão escolar democrática, a criação dos Conselhos e Grêmios Estudantis, a elaboração do Projeto Político-pedagógico no âmbito interno, escolha direta de diretores, dentre outros.

A questão é complexa, pois identificamos, na atual conjuntura que perpassa a eleição de diretores como instrumento de gestão democrática, resquícios de patrimonialismo. ${ }^{1}$ Devido à especificidade do Estado brasileiro, esse fator interfere nas formas de provimento na eleição de diretores, repercutindo na discussão sobre a qualidade da Educação Básica, tal como na valorização docente. Assim, o objeto prioritário deste artigo advém de revisão bibliográfica e documental, bem como, de consulta a dados públicos e análise da Lei $n^{\circ} \cdot 3.992 / 2015$, a qual dispõe sobre as eleições para Diretores nos Centros Municipais de Educação Infantil e nas Escolas dos Anos Iniciais do Ensino Fundamental.

Sabe-se que o princípio da gestão democrática é constantemente difundido, bem como, sua repercussão para a qualidade educacional, mas a discussão sobre como, quando e de que forma a gestão democrática se manifesta ainda articula e proporciona inúmeras problemáticas de diversos estudos, conforme outros aportes teóricos e perspectivas metodológicas.

A referida rede escolar municipal é constituída por 29 escolas dos Anos Iniciais do Ensino Fundamental, que atendem a 4.702 alunos e contam com cerca de 390 professores. No entanto, é responsável por 12 Centros Municipais de Educação Infantil, atendendo a 728 alunos, e contam com cerca de 190 professores (levantamentos estatísticos, 2017). ${ }^{2}$

\footnotetext{
A concepção liberal no Brasil conciliou a natureza patrimonialista do Estado Brasileiro e um regime monárquico de base jurídico-liberal. Os conservadorismos da elite política brasileira exerceram forte impacto sobre o processo de democratização nos limites do capital. Nessa conjuntura, a formação do Estado Nacional Brasileiro é marcada pelas relações de poder pessoal, um modelo patrimonialista desde o período colonial. Com a Independência em 1822, o Estado passou a acomodar uma ordem patrimonialista (pessoalidade, o espaço público é entendido como propriedade do gestor) e a ordem racional-legal (impessoalidade, separação entre o espaço público e privado). A presença desses dois modelos marcou o processo de formação do Estado Nacional e se tornou um obstáculo para a efetivação da democracia burguesa (CHAVES, 2007).

2 Dados estatísticos obtidos mediante pesquisa no site da Secretaria Municipal de Educação de um município pertencente à Mesorregião Sudeste do Paraná. Optamos por não mencionar o nome do município, devido ao caráter documental e empírico deste estudo.
} 
Como já destacamos, este estudo inicial possui, como perspectiva, verificar o processo de eleição para diretores na Educação Infantil e Anos Iniciais e de que forma os princípios da gestão democrática estão sendo utilizados na promoção da valorização docente.

Organizamos os dados em dois momentos. No primeiro, abordamos as especificações referentes às formas de provimento. Também, como esse instrumento repercute na eleição para diretores, adquirindo preceitos da gestão democrática e promovendo a valorização docente, desenvolvendo um paralelo com a análise do potencial patrimonialista ou princípios tecnocráticos nos processos de gestão escolar no município estudado.

Em um segundo momento, analisamos a Lei $n^{\circ}$. 3.992/2015, contextualizando-a conforme os dados públicos referentes ao processo de eleição de gestores de um município localizado na Mesorregião Sudeste do Estado do Paraná. Ainda, como estas informações interferem na constituição dos espaços escolares, como ambientes que proporcionam a valorização docente, sendo esse um dos fatores que repercutem na qualidade do ensino.

O presente estudo não buscou discutir todas as teorias que abarcam a democracia e a gestão democrática da escola, mas ponderar, sobre um caso específico, as formas de provimento na Educação Básica pública. O espaço de pesquisa constitui-se nos Centros Municipais de Educação Infantil e as Escolas dos Anos Iniciais do Ensino Fundamental, observando a aplicabilidade dessas formas, bem como, a identificação de mecanismos que proporcionam a valorização do trabalho docente. Também buscou perceber, por meio dos dados públicos, a ação desses mecanismos para tentar atingir o pressuposto do sistema público democrático, a eleição dos responsáveis pela gestão das escolas públicas.

\section{As FORMAS DE PROVIMENTO E SUAS IMPLICAÇÕES NA TEORIA DA GESTÃO DEMOCRÁTICA NO CONTEXTO DA EDUCAÇÃO BÁSICA PÚBLICA: BREVE CONTEXTUALIZAÇÃO HISTÓRICA}

O conceito de democracia é complexo, abarca inúmeras interfaces. Se fôssemos considerar seu sentido mais popular, parece até uma função impossível considerar todos os posicionamentos em torno do bem comum, priorizando aquilo que é público e de direito de todos os cidadãos.

Ao mencionar a influência da democracia na Educação Básica pública, consideramos que a escola recebeu e continua recebendo inúmeras influências dos mais diversos contextos da sociedade. Quando nos deparamos com a ideia de gestão da escola, por vezes não sabemos como mediar o viés participação, que objetiva o bem comum da função social da escola, visto que a atual estrutura da escola pública é permeada por metas, planejamentos, planos de ensino e/ou trabalho e avaliações. Essas características são oriundas de um sistema educacional que se apresentou com o período de efervescência da industrialização e das Teorias Administrativas do século XIX. ${ }^{3}$

Por sua vez, o advento da revolução industrial desencadeou, nas escolas, uma conjuntura que se baseia no viés empresarial, e quando os espaços escolares adotam essa postura, tomam por referência somente aspectos burocráticos. Muitas vezes, deixam em segundo plano as particularidades culturais, que permeiam as características básicas da instituição escolar.

\footnotetext{
É pertinente ressaltar alguns dos princípios da administração científica e seus principais precursores. Destacamos as influências do pensamento de Frederick W. Taylor (1856-1915), proveniente dos Estados Unidos. Suas ideias administrativas partiam da eliminação de desperdícios, caráter científico dos processos produtivos e eficiência da empresa. Por sua vez, no contexto europeu, mais precisamente na França, Henri Fayol (1841-1925) introduz a administração como ciência, propondo a previsão, o comando, a organização, a coordenação e o controle, salientando a ênfase na estrutura e funcionamento da empresa.
} 
Logo, partimos do pressuposto que a gestão da educação tem como incumbência propiciar condições para a qualidade educativa, pois se caracteriza como uma das formas de humanizar e de formar cidadãos. Os princípios da gestão convergem para que os objetivos da Educação, enquanto função social, forneçam o domínio dos conteúdos necessários para a prática do trabalho, em um ensino que atenda e respeite as diversidades existentes na realidade atual, estabelecendo, com isso, a construção de uma sociedade mais justa em um contexto geral. É importante salientar que é pela gestão que essas finalidades serão cumpridas.

Assim, pautamo-nos nas considerações de Dourado (2001, p. 79, grifo do autor):

[...] a gestão democrática é entendida como um processo de aprendizado e de luta política que não se circunscreve aos limites da prática educativa mas vislumbra, nas especificidades dessa prática social e de sua relativa autonomia, a possibilidade de criação de canais de efetiva participação e de aprendizado do jogo democrático e, conseqüentemente (sic), do repensar das estruturas de poder autoritário que permeiam as relações sociais e, no seio dessas, as práticas educativas.

Tentar conceituar a democracia é intrínseco, pois em diferentes tempos e realidades se encontraram formas distintas do fazer democrático, para além da neutralidade, e dotado de inúmeros significados. Nessa perspectiva e devido à grande quantidade de significados, a relação com o termo participação incorporou-se no contexto político a partir do final do século $X X$, sendo consensual entre as esferas políticas, consideradas opostas de acordo com a estrutura e classe social. Com isso e mediante as diversas oposições colocadas ao conceito de democracia, tomamos por referência a conceituação de Bobbio (2000, p. 387), em que ressalta o sis- tema democrático como contrário ao regime de cunho autoritário:

[...] A definição de democracia como poder em público não exclui naturalmente que ela possa e deva ser caracterizada também de outras maneiras. Mas essa definição capta muito bem um aspecto pelo qual a democracia representa uma antítese de todas as formas autocráticas de poder.

A gestão escolar caracteriza-se como processo político que age como disputa de poder, que possui como tarefa executar as políticas educacionais. Logo, Ugarte (2004, p. 94) salienta: "[...] uma democracia digna de ser justificada corresponde a certos tipos de participação e cidadania".

A colocação de Ugarte (2004) converge para o caráter educativo de formação para a vivência cidadã. A gestão democrática possui esse princípio em sua essência, ao partir da premissa que uma sociedade só é igualmente democrática quando possibilita a participação efetiva de todos. Essa situação, ao ser implicada na rotina da escola, converge para que todos os agentes escolares estejam presentes na gestão do projeto de trabalho escolar, dotados não só de formação teórica, também humana. Sobre esse assunto, Ferreira (2010, p. 167) esclarece que:

[...] a gestão democrática da Educação é hoje um valor já consagrado no Brasil e no mundo, embora ainda não totalmente compreendido e incorporado à prática social global e à prática educacional brasileira e mundial. É indubitável sua importância como um recurso de participação humana e de formação para a cidadania. É indubitável sua necessidade para a construção de uma sociedade mais justa e igualitária. É indubitável sua importância como fonte de humanização. 
Entretanto, por vezes, há o estabelecimento do sentido que democracia e participação são similares, porque se procede à ideia de que as decisões perpassam grande parte da população, o entendimento de que basta a participação de todos, e/ou da maioria, desde a elaboração até a efetivação de uma política e/ ou programa, para que receba a denominação de que vivemos em um sistema democrático.

A participação cidadã e a democracia foram, aos poucos, sendo construídas por meio da luta de muitos educadores. Dessa forma, os progressos no contexto da administração da Educação se materializaram na elaboração da Constituição Federal, datada de 5 de outubro de 1988. Para o estudo das formas de provimento como princípio da gestão democrática da escola e da qualidade do sistema público, ressaltamos o Artigo 206, que determina:

O ensino será ministrado com base nos seguintes princípios:

I - igualdade de condições para o acesso e permanência na escola; II - liberdade de aprender, ensinar, pesquisar e divulgar o pensamento, a arte e o saber;

III - pluralismo de ideias e de concepções pedagógicas, e coexistência de instituições públicas e privadas de ensino;

IV - gratuidade do ensino público em estabelecimentos oficiais;

$V$ - valorização dos profissionais do ensino, garantindo, na forma de lei, plano de carreira para o magistério público, com piso salarial profissional e ingresso exclusivamente por concurso público de provas e títulos, assegurado regime jurídico único para todas as instituições mantidas pela União;

VI - gestão democrática do ensino público, na forma de lei;

VII - garantia de padrão de qualidade (BRASIL, 1988).
As demandas regulamentadas em forma de lei, pela Carta Magna de 1988, fizeram que a educação, mais especificamente a etapa que compreende o ensino básico público, passasse a ser entendido como algo que merece atenção e investimentos por parte do público municipal e dos demais elementos que correspondem ao princípio de horizontalidade. Esse fator predominante na constituição do Estado Federado toma, como ponto de partida, o presente referencial da educação básica, para que corresponda aos objetivos e funções sociais que lhe são impostos historicamente, tanto aqueles que convergem para o processo de ensino-aprendizagem, como para a gestão democrática da escola. Nessa perspectiva, destacamos o que está posto na Lei $n^{\circ}$.9. 394, de 20 de dezembro de 1996:

Artigo 14 - Os sistemas de ensino definirão as normas de gestão democrática do ensino público na educação básica, de acordo com suas peculiaridades e conforme os seguintes princípios:

I - participação dos profissionais da Educação na elaboração do projeto pedagógico da escola;

II - participação das comunidades escolar e local em conselhos escolares ou equivalentes (BRASIL, 1996).

O artigo mencionado está relacionado ao que predispõe o Artigo 206 da Constituição Federal de 1998, partilhando da afirmação de que a gestão democrática da Educação precisa ser desenvolvida, organizada e exercida cotidianamente. Dessa forma, ressaltamos o Artigo 15 da Lei $n^{\circ}$. 9.394/96, que estabelece que "os sistemas de ensino assegurarão às unidades escolares públicas de Educação básica que os integram progressivos graus de autonomia pedagógica, administrativa e de gestão financeira, observadas as normas gerais de direito financeiro público" (BRASIL, 1996).

Contudo, ao tratar de mecanismos que objetivam a qualidade de ensino, atentamos que, atualmente, a gestão é entendida como 
o espaço responsável para desempenhar essa tarefa no contexto das escolas públicas. A partir desta afirmação, ressaltamos o parecer de Ferreira (2006, p. 170-171, grifo do autor):

[...] é administração, é tomada de decisão, é organização, é direção.

Relaciona-se com a atividade de impulsionar uma organização. É um termo que, historicamente, vem se afirmando no âmbito da administração da educação e no estudo das instituições e organizações, incluindo as educacionais, como sinônimo de administração, e que se instala no mundo pensante com um sentido mais dinâmico, traduzindo movimento, ação, mobilização, articulação.

O paralelo entre intenção e ação, quando ambas as funções tornam capazes a previsão e singela possibilidade de observar resultados futuros por meio do planejamento, faz da gestão, além de ser o processo, ser o meio e também o fim. Ao mencionarmos a familiaridade dos termos administração e gestão escolar, é no sentido que Libâneo (2004, p. 101) expressa: "[...] a atividade pela qual são mobilizados meios e procedimentos para se atingir os objetivos da organização, envolvendo, basicamente, os aspectos gerenciais e técnicos-administrativos. Neste sentido, é sinônimo de administração".

$\mathrm{Na}$ estrutura da escola, gestão e administração estão presentes diariamente. A forma como os profissionais estabelecem as normas dentro do contexto escolar predispõe as maneiras de gerir o corpo docente, discente, materiais e recursos. E essa ação é desenvolvida de acordo com a nossa formação humana, nos adequamos ao sistema que opera, introduzindo suas falas em nossas práticas cotidianas.

Salientamos que a maneira como os profissionais da Educação estabelecem as regras nos espaços de ensino divergem, de acordo com as formas de provimento que cada ges- tor passou até chegar à direção de uma escola ou outro espaço educativo.

O sistema de eleição para provimento nos órgãos públicos educacionais iniciou no período de redemocratização política do país. Em muitos locais, Estados primeiramente, iniciou o processo de eleição de seus governantes. Todavia, não foi uma ação totalmente aceita, como constatamos em Paro (1996, p. 377):

Embora algumas experiências localizadas remontem à década de 60 , a reivindicação da escolha de diretores escolares por meio de processo eletivo, em âmbito nacional, é fenômeno que se inicia nos começos da década de 80, no contexto da redemocratização política do país. Em vários Estados, iniciam-se processos de eleição de diretores escolares na primeira metade dessa década, com a ascensão dos primeiros governadores estaduais eleitos, após a ditadura iniciada em 1964. Em 1989, vários Estados inscrevem em suas constituições a obrigatoriedade da eleição como critério de escolha dos diretores nas escolas públicas. Entretanto, já ao final da década de 80 e início da de 9o, verifica-se certo refluxo das eleições em alguns Estados, produto da ação de governos pouco comprometidos com a democracia, que entram com Ações Diretas de Inconstitucionalidade contra as eleições, com a clara intenção de proteger seus interesses político-partidários identificados com práticas clientelistas.

Por muito tempo, adotar o processo eletivo como critério para a escolha de gestores na educação pública municipal passou por muitas interfaces. Contudo, a partir dos anos 1980, a nomeação política abre espaço para a eleição para os cargos públicos. De acordo 
com Paro (1996), os Estados do Paraná e do Distrito Federal foram os primeiros entes federados a adotarem a escolha democrática de diretores. Muitas vezes, esse posicionamento indicava o compromisso político de muitos governantes com suas promessas de campanhas eleitorais.

Não podemos esquecer que não eram somente os governantes em períodos eleitorais que se interessavam pelo processo democrático na eleição de diretores. Essa exigência, se é que assim pode ser chamada, era pauta de muitos movimentos sociais e de minorias imersas no universo da escola, que acreditavam e lutavam pela gestão democrática da escola e, principalmente, por uma educação pública e de qualidade.

Ainda, conforme descreve Paro (1996), destacamos algumas perspectivas para a implantação do processo de eleição para diretores. Existia a premissa de que, mediante um sistema eletivo, práticas tradicionalistas e influências político-partidárias permeadas pelo clientelismo seriam superadas; seria eliminado do autoritarismo, possibilitando a participação de todos os atores escolares nas decisões que se relacionam com a realidade e o futuro da escola; também a ideia do corporativismo, que se baseia no fundamento de que somente porque foi eleito deve fazer as vontades da maioria que o colocou no cargo de gestão, favorecendo, com isso, pequenos grupos em troca de apoio político, em candidaturas futuras. Dessa forma, Paro (1996, p. 381) ressalta que:

[...] uma importante característica das eleições é que, como todo processo de democracia, a participação e o envolvimento das pessoas, enquanto sujeitos na condução das ações, é apenas uma possibilidade, não uma garantia. Especialmente em sociedades com fortes marcas tradicionalistas, sem uma cultura desenvolvida de participação social, é muito difícil conseguir-se que os indivíduos não deleguem a outros aquilo que faz parte de sua obrigação, enquanto sujeito partícipe da ação coletiva. No caso da escola pública, as reclamações, especialmente de diretores, dão conta de que a eleição do dirigente acaba, em grande medida, significando não a escolha de um líder para a coordenação do esforço humano coletivo na escola, mas muito mais como uma oportunidade de jogar sobre os ombros do diretor toda a responsabilidade que envolve a prática escolar.

A gestão democrática da escola necessita ser compreendida como um processo dinâmico, em que não é o trabalho de um representante eleito que fará que se atinja a qualidade educacional, mas uma tarefa que envolve todos que fazem parte da realidade da escola. A democracia perpassa pela crença em fazer ouvir e fazer falar todas as falas ocultas que permeiam o contexto escolar. Nesse cenário, o papel do diretor escolar na atual conjuntura que está inserida a escola não pode se referir à "mera delegação de poderes" (DOURADO, 1990, p. 139). É pertinente, portanto, que todos os sujeitos envolvidos, que são produto e produtores da escola, ajudem e estejam preparados para exercer a condição de fazer parte de um contexto escolar democrático, para que o exercício de diretor não se perca no isolamento e na solidão.

É pertinente mencionar que, por vezes, nos afastamos de uma posição democrática, que pode ser medida não só quando exercemos papéis de chefia, mas em nosso dia a dia. Será somente pela formação humana, tomando por base mecanismos de participação e de exercício da democracia, que chegaremos a envolver todos os sujeitos da escola. Cada um, com suas responsabilidades, fomentará a construção, primeiramente em uma escola para, posteriormente, elucidarmos a ideia de uma sociedade verdadeiramente democrática.

Porém, ao que concerne à gestão democrática da escola, não podemos deixar de ressal- 
tar as formas de provimento que se instalaram nas escolas públicas brasileiras. Segundo Dourado (2001), na década de 1980, as formas mais usuais compreendiam: "1) diretor livremente indicado pelos poderes públicos (estados e municípios); 2) diretor de carreira; 3) diretor aprovado em concurso público; 4) diretor indicado por listas tríplices ou sêxtuplas; 5) eleição direta para diretor" (DOURADO, 2001, p. 83).

A forma como o diretor escolar é escoIhido atualmente, no Brasil, converge para a estrutura das políticas educacionais, sendo estas inseridas em uma política maior, do Estado. Ao estabelecer, na Constituição de 1988, a gestão democrática como princípio, e logo em seguida regulamentá-la na LDB 9.394/96, o governo federal articula diversas estratégias para garantir que uma lei, decreto ou programa seja implementado.

Tanto a Carta Magna de 1988 como a Lei de Diretrizes e Bases da Educação Nacional (Lei $n^{\circ}$. 9.394/96) foram importantes elementos para tornar as escolas espaços participativos. Contudo, como vivemos na égide da estrutura que compõe o Estado Federado, cada ente federativo busca adequar-se de acordo com suas particularidades, ou seja, formas para que estes princípios sejam implementados. Considerando que a escola não é um fim, mas um todo, é no contexto educativo que determinada política educacional se efetiva. Nessa perspectiva, as formas de provimento para o cargo de gestor escolar se inserem nas diversas medidas que foram implantadas pelos governos, destaque para a Resolução nº 04/2010 (BRASIL, 2010), que expressa o projeto político-pedagógico como um dos mecanismos de proporcionar a gestão democrática, que se caracteriza como o eixo norteador da organização do trabalho pedagógico da escola.

\section{AS FORMAS DE PROVIMENTO NO CONTEXTO DA GESTÃO DEMOCRÁTICA eM um Município da Mesorregião Sudeste do Estado do Paraná}

Ao iniciar o nosso estudo, deparamo-nos com uma problemática pertinente. Par- tindo do princípio que a gestão democrática da escola é assegurada por leis e decretos, será que o município, objeto de nosso estudo, perpassa os mecanismos que asseguram um sistema de ensino democrático? E para tentar responder a nossa indagação, o percurso de pesquisa caracterizou-se pela busca nos sites da Prefeitura Municipal, bem como no site da Secretaria Municipal de Educação. Consultamos alguns dados públicos referentes à gestão das escolas dos Anos Iniciais do Ensino Fundamental e dos Centros Municipais de Educação Infantil.

A questão, citada no parágrafo anterior, permeia outra indagação, que converge para a valorização do trabalho docente, bem como, do gestor educacional. No presente estudo, pautamo-nos no conceito formulado por Grochoska (2016, p. 01-02), quando afirma que:

[...] a valorização docente está diretamente ligada a elementos que promovem esta condição, como: Formação, formação inicial e continuada, planos de carreira, remuneração, piso, carreira, condições físicas do local de trabalho, autonomia profissional, organização da carreira ou condições de trabalho, como estabilidade, carga horária. Tais elementos não surgem do nada, são reflexos das disputas que levam as condições de trabaIho do professor em documentos e leis nacionais.

A valorização profissional ainda é luta constante no dia a dia dos professores. Contudo, foram essas mobilizações que transformaram muitos direitos, que estavam somente nas pautas dos discursos dos governantes, em realidades concretas. Destacamos, como exemplo, a Lei $n^{\circ}$. 3.992/2015 (PREFEITURA MUNICIPAL, 2015), que regulamenta a escoIha de diretores para as escolas municipais, uma reivindicação da classe docente desde a 
elaboração do primeiro Plano de Carreira do Magistério Municipal. ${ }^{4}$

Contudo, a Lei $n^{\circ}$. 3.992/2015 esclarece alguns critérios para o processo de eleição para diretores nas escolas municipais:

Artigo $2^{\circ}$. - A eleição para diretor das Escolas da Rede Municipal de Ensino será realizada nos estabelecimentos que atendem o porte de no mínimo 50 alunos, respeitada a duração do mandato previsto nesta Lei, conforme cronograma estipulado pela Secretaria Municipal de Educação (PREFEITURA MUNIClPAL, 2015).

Considerando o Artigo $2^{\circ}$., da Lei $n^{\circ}$. 3.992/15, estipular a quantidade de alunos como critério para a realização de eleições para diretores é excludente. Isso porque distancia muitas escolas e Centros Municipais de Educação Infantil da realidade da gestão democrática, limitando o processo ao número de alunos.

Há que se destacar que os planos de carreira dos professores que compõem os Anos Iniciais e o processo de eleição para diretores já sofreram alterações, de acordo com as novas leis, tanto municipais como estaduais e/ou federais. Por sua vez, os profissionais da Educação Infantil ainda não tiveram alteração em seu plano de carreira, estando vigente, até o presente momento, a Lei $n^{\circ}$. 2.806/2008.

Essa situação é de difícil clareza, pois se a gestão democrática está alicerçada na qualidade do ensino público, as leis não poderiam ficar inertes à realidade política. A conjuntura atual possui, como característica, um intermitente retrocesso, no que tange aos direitos sociais para a educação pública, também trazendo reflexos negativos para os direitos dos docentes. Diante dessa problemática, Frigotto (2009, p. 65) esclarece que:

4 O primeiro plano de carreira para os professores dos Anos Iniciais do Ensino Fundamental (2oh) é respaldado pela Lei $n^{\circ}$. 2.321/2005. No que tange aos professores que compõem a Educação Infantil, regime 40h, o primeiro plano de carreira é respaldado pela Lei $n^{\circ}$. 2.806/2008.
O tempo histórico contemporâneo, como o descreve uma vasta literatura crítica, caracteriza-se pela regressão social, indeterminação política e pela hegemonia de concepções neoconservadoras e mercantis na sociedade e nos processos educativos. Essa regressão ganha especificidade e particularidade em nosso processo de formação histórico-social.

O sentido empregado ao termo retrocesso corresponde ao fato de que a Educação Infantil não acompanha as disposições colocadas pela lei para eleição de diretores, visto que, nesse espaço, a escolha é feita por indicação.

Em contrapartida, a aprovação da Lei $n^{\circ}$. 3.992, de 16 de junho de 2015, estabeleceu as normas para as eleições de diretores das escolas municipais do município, objeto desta análise. A presente lei representa grande avanço, no que diz respeito à participação política, bem como à gestão democrática da escola, até porque obteve boa aceitação pela comunidade escolar. Porém, existe um ponto importante a ressaltar, visto que não são todas as escolas municipais que adotaram o processo de eleição, como trata o parágrafo único, da Lei nº 3.992/2015:

O Processo Eleitoral não será realizado nas escolas em que o prédio é mantido por congregações religiosas, bem como na direção geral do CAIC (Centro de Atendimento Integral à Criança), sendo que os diretores dessas unidades serão indicados, desde que atuem como professores da rede:

I - pela própria congregação religiosa no caso das escolas que funcionem em prédios sob sua responsabilidade; II - pelo (a) Secretário (a) Municipal de Educação no caso do CAIC. 
Conforme as informações já descritas, percebemos que o processo eleitoral não é uma unanimidade em todas as escolas: algumas seguem regras próprias, como é o caso dos Centros de Atendimento Integral à Criança (CAIC), e as escolas mantidas por congregações religiosas. Assim sendo, a eleição para diretores, que é um elemento da gestão democrática, não se aplica a todas as realidades escolares no presente município.

Sob outra perspectiva, um ponto que, em nosso ver, merece destaque, é o critério de indicação, ainda bastante presente, principalmente no contexto da Educação Infantil: nesse espaço, como já mencionamos, não ocorre processo de eleição.

Outra questão que se coloca é que atualmente as professoras que estão à frente dos Centros Municipais de Educação Infantil não são todas concursadas nessa respectiva etapa, somente $81 \%$ das profissionais que estão na gestão dos Centros Municipais de Educação Infantil são concursadas como professoras dessa área.

A colocação mencionada revela certa (des)valorização para com a Educação Infantil, excluindo do processo de eleição para diretores, do mesmo modo que não se exige que quem esteja à frente dos espaços de ensino, responsáveis pelo desenvolvimento integral das crianças de 0 a 5 anos de idade, seja concursado na área de atuação.

Há outro possível indicador de (des) valorização para com a Educação Infantil, e este se refere à porcentagem que compõe o suporte pedagógico. Este vem a ser um valor acrescido à folha de pagamento dos docentes, quando estes exercem a função de diretor e/ou coordenador escolar. Nesse contexto, os profissionais que atuam na gestão dos Centros Municipais de Educação Infantil recebem o suporte pedagógico equivalente a $30 \%$, de tal maneira que, para os docentes que assumem a gestão nas escolas dos Anos Iniciais do Ensino Fundamental, o valor corresponde a $35 \%$ acrescidos à sua remuneração como professor. ${ }^{5}$

5 Informação disponibilizada via e-mail, pela responsável pela documentação escolar e recursos humanos da Secretaria Municipal de Educação.
Conforme as informações já apresentadas, podemos elucidar, mediante estes dados preliminares, que tanto a gestão democrática da escola, como a valorização docente ainda possuem um longo caminho de luta na efetivação dos direitos dos docentes e todos os envolvidos na conjuntura da escola básica pública, principalmente nos contextos que permeiam a Educação Infantil e os Anos Iniciais do Ensino Fundamental.

A gestão, partindo do princípio democrático de participação de toda a comunidade escolar no processo de eleição, ainda não é uma realidade concreta, pois se encontram muitas formas mistas de escolha para o cargo de gestor. A educação para a democracia, principalmente no que se refere à gestão das escolas é, nas palavras de Paro (1996), uma nova situação para o diretor. Assim, expõe:

Passar de uma fase clientelística,
onde o que vale é o critério político
partidário, para uma situação de es-
colha democrática, legitimado pela
vontade dos sujeitos envolvidos na
situação escolar, faria supor, para
muitos, mudanças significativas no
perfil do diretor da escola pública
básica (PARO, 1996, p. 382-383).

A gestão escolar e o papel do diretor necessitam ser pensados sob outra perspectiva, um novo paradigma que converge para a participação cidadã, embasado por uma nova forma de pensar a sociedade democrática. Em outras palavras, uma nova percepção de participação cidadã, tanto nas questões pertinentes ao processo de adoção do sistema democrático da escola, como na valorização do trabalho docente, até porque aqueles que estão à frente dos estabelecimentos municipais de ensino são, em primeiro lugar, professores.

\section{CONSIDERAÇÕES FINAIS}

A análise desenvolvida mediante dados preliminares sobre as formas de provimento 
na gestão básica pública, inserida no contexto do município analisado, apontou algumas discrepâncias no processo para a eleição de diretores. Constatamos que não são todas as escolas que partilham do processo eleitoral e, ainda, a Educação Infantil não está vinculada às especificidades da Lei $n^{\circ}$. 3.992/2015.

Conforme o que mencionamos no início deste estudo, a possibilidade de fusão entre a gestão democrática da escola com a qualidade do ensino público está na perspectiva de que o sucesso escolar se constrói por meio da participação e da gestão escolar. Dessa forma, ressaltamos o pensamento de Apple e Beane (1997, p. 154-155): “[...] o significado mais poderoso da democracia não é formado pela capciosa retórica política, mas nos detaIhes da vida cotidiana".

A afirmação dos autores predispõe que os atores escolares necessitam participar de cada momento e questão que permeiam a escola, cooperando e participando para que esses espaços consigam atingir os seus objetivos. O compromisso dos sujeitos que compõem a educação básica pública predispõe estar comprometidos e envolvidos no que denominamos de cultura de nós, para que a gestão democrática da escola se efetive.

Sinalizamos que a valorização docente dos professores que assumem a gestão dos Centros Municipais de Educação Infantil e das
Escolas dos Anos Iniciais necessita ser uma realidade concreta. Identificamos que nas escolas, salvo exceções específicas da Lei $n^{\circ}$. 3.992/2015, as formas de provimento para o cargo de diretor já estão concretizadas. Contudo, na etapa que compreende a Educação Infantil, nas funções que correspondem à gestão da Educação, ainda predomina o caráter patrimonialista.

Assim, apontamos que a valorização dos professores municipais necessita, ainda, ser percebida sob o ponto de vista do direito dos trabalhadores docentes; e a gestão democrática da educação pública, como pressuposto básico de uma sociedade democrática. É pertinente a troca das ideias antidemocráticas na escola e na sociedade, mediante o desenvolvimento de uma consciência política, mas também humana, tanto a valorização dos profissionais que compreendem o magistério público, quanto as formas de provimento e sua repercussão na gestão democrática da escola. Estas são questões complexas.

Contudo, salientamos a necessidade de enfrentá-las em contexto de lutas e mobilizações para que, talvez, em um futuro próximo, os direitos tanto a uma carreira bem estruturada e com o devido reconhecimento e quanto a processos democráticos para eleição de diretores, permeado pela efetiva participação da comunidade escolar e social, não sejam somente uma utopia.

\section{REFERÊNCIAS}

APPLE, M.; BEANE, J. Escolas democráticas. São Paulo: Cortez, 1997.

BOBBIO, N. Liberalismo e democracia, 6. ed. São Paulo: Brasiliense, 2005.

BRASIL. Constituição Federal. Constituição: República Federativa do Brasil. Brasília: Senado Federal, 1998.

. Resolução $n^{\circ}$. 4, de 13 de julho de 2010. Define as Diretrizes Nacionais Gerais para a Educação Básica. Brasília, MEC/CNE, 2010.

Disponível em: <http://portal.mec.gov.br/dmdocuments/rcebo04_10.pdf>. Acesso em: 27 abr. 2018. 


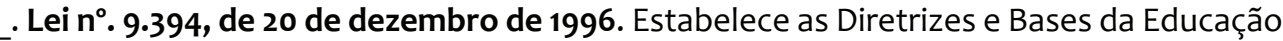
Nacional. Brasília, MEC/INEP, 1996.

CARVALHO, E. J. G. de; PAINI, L. D.; CROCE, M. L.; ALTOÉ, N. CARBELLO, S. R. C. (Orgs.). Gestão escolar. Secretaria de Estado da Educação do Paraná: Universidade Estadual de Maringá, 22. ed. 2008.

Disponível em: <http://www.gestaoescolar.diaadia.pr.gov.br/arquivos/File/producoes_pde/ md_elaine_sinhorini_arneiro.pdf >. Acesso em: 13 jun. 2017.

DOURADO, L. F. A escolha dos dirigentes escolares: políticas e gestão da educação no Brasil. In: FERREIRA, N. S. C. (Org.). Gestão democrática da educação: atuais tendências, novos desafios, 3. ed. São Paulo: Cortez, 2001.

DOURADO, L. F. Democratização da escola: eleições de diretores, um caminho? Dissertação (Mestrado) - Faculdade de Educação da Universidade Federal de Goiás - UFG, Goiânia, 1990.

Disponível em: <http://ppge.fe.ufg.br/uploads/6/original_Dissert-_Luiz_Fernandes_Dourado. pdf>. Acesso em: 25 mai. 2017.

ESQUISANI, R. S. S. Eleição de diretores e gestão da escola pública: reflexões sobre democracia e patrimonialismo. Revista Nuances: estudos sobre Educação, Presidente Prudente/SP, v. 24, n. 2, p. 101-115, mai./ago. 2013. Disponível em: <http://revista.fct.unesp.br/index.php/Nuances/ article/view/2482>. Acesso em: 5 jun. 2017.

FERREIRA, N. S. C. Gestão democrática da educação na formação do profissional da educação. In: FERREIRA, N. S. C. (Org.). Políticas públicas e gestão da educação: polêmicas, fundamentos e análises. Brasília: Liber Editora Ltda., 2006, p. 157-176.

. Supervisão educacional no Brasil: trajetória de compromissos no domínio das políticas públicas e da administração da educação. In: FERREIRA, N. S. C. Supervisão educacional. Supervisão educacional para uma escola de qualidade, 8. ed. São Paulo: Cortez, 2010, p. 235-254.

FRIGOTTO, G. Política e gestão educacional na contemporaneidade. In: FERREIRA, E. B.; OLIVEIRA, D. A. (Org.). Crise da escola e políticas educativas. Belo Horizonte-MG: Autêntica, 2009, p. 65-80.

GROCHOSKA, M. A. Valorização do professor: a trajetória das legislações que regulamentam a carreira dos professores de educação básica no município de São José dos Pinhais. XI ANPED SUL. Reunião Científica Regional da ANPED. Educação, movimentos sociais e políticas governamentais, 24 a 27 de julho de 2016, UFPR - Curitiba-PR.

HYPÓLITO, Á. M.; LEITE, M. C. L.; DALL'IGNA, M. A.; MARCOLLA, V. Gestão educacional e democracia participativa. Porto Alegre: Editora da UFRGS, 2008.

LIBÂNEO, J. C. Organização e gestão escolar: teoria e prática, 5. ed. Goiânia: Alternativa, 2004. PARO, V. H. Eleições de diretores de escolas públicas: avanços e limites da prática. Revista bras. Est. pedag., v. 77, n. 186, p. 376-395, mai./ago. Brasília, 1996.

Disponível em: <http://rbep.inep.gov.br/index.php/rbep/article/viewFile/1084/1058>. Acesso em: 12 jun. 2017.

PREFEITURA MUNICIPAL. Lei $\mathbf{n}^{\circ} \mathbf{.} \mathbf{2 . 8 0 6}$, de 25 de novembro de 2008: Expõe a nova denominação ao cargo de Monitor de Creche, inclui seus ocupantes no Plano de Carreira do Magistério Municipal e dá outras providências, 2008. 
Disponível em: <https://valorizacaodocente.files.wordpress.com/2018/02/lei-nc2ba-2806-08-irati-plano-de-cargos-professor-40h.pdf>. Acesso em: 27 abr. 2018.

PREFEITURA MUNICIPAL. Lei nº 3.992, de 16 de junho de 2015. Regulamenta o processo de eleição para diretores nas escolas municipais, 2015. Disponível em: <http://educacao.irati.pr.gov.br/ noticias/legislacaofederal/dire.PDF>. Acesso em: $1^{\circ}$. jun. 2017.

UGARTE, P. S. Que participação para qual democracia? In: COELHO, Vera Schattan P.; NOBRE, Marcos. Participação e deliberação: teoria democrática e experiências institucionais no Brasil contemporâneo. São Paulo: Editora 34, p. 93-103, 2004.

\section{SOBRE AS AUTORAS}

\section{MARIA LETÍ́CIA NEVES}

Mestranda em Educação, pelo Programa de Pós-Graduação (PPGE), da Universidade Estadual do Centro-Oeste, Campus Irati (PR).

E-mail: le_neves2007@hotmail.com

\section{MARISA SCHNECKENBERG}

Professora Associada da Universidade Estadual do Centro-Oeste atuando no Curso de Licenciatura em Pedagogia e no Programa de Pós-Graduação em Educação, da Universidade Estadual do Centro-Oeste, Campus Irati (PR).

E-mail: marisaunicentro@hotmail.com

\section{MiCHELLE FERNANDES LIMA}

Professora da Universidade Estadual do Centro-Oeste: Campus Irati (PR), nas disciplinas de Metodologia da Pesquisa em Ciências da Educação e Políticas Educacionais. Professora do Programa de Pós-Graduação em Educação, da Universidade Estadual do Centro-Oeste, Campus Irati (PR).

E-mail: mfernandeslima@yahoo.com.br

Recebido em: 30 de abril de 2018

Aprovado em: 15 de junho de 2018 